\title{
RETRACTION
}

\section{Reprogramming bacteria to seek and destroy an herbicide}

\author{
Joy Sinha, Samuel Reyes \& Justin P Gallivan
}

Nat. Chem. Biol. 6, 464-470 (2010); published online 9 May 2010; retracted 14 February 2014

We wish to retract our article entitled "Reprogramming bacteria to seek and destroy an herbicide."

While performing further studies on the riboswitch reported in the article, a postdoctoral researcher in our laboratory was unable to reproduce the results reported in Figure 4. Specifically, neither atrazine-dependent changes in $\beta$-galactosidase activity (Fig. $4 \mathrm{a})$ nor changes in motility (Fig. 4b,c) were observed. Upon learning this, J.P.G. asked a second postdoctoral researcher with expertise in synthetic riboswitches to carry out the experiments. Again, no significant atrazine-dependent changes in $\beta$-galactosidase activity or motility were observed. Because atrazine-dependent changes in gene expression formed the central thesis of the paper, we feel that retraction of the work in its entirety is essential.

At the request of J.P.G., the Emory University Office of Research Compliance conducted an independent inquiry. The inquiry committee concurred with the authors' decision to retract the article based on the irreproducibility of the results.

We sincerely apologize to the scientific community for any harm caused by this publication.

\section{RETRACTION}

\section{Designer bacteria degrades toxin}

John R Kirby

Nat. Chem. Biol. 6, 398-399 (2010); published online 17 May 2010; retracted 14 February 2014

In view of the fact that the authors of "Reprogramming bacteria to seek and destroy an herbicide" are retracting their report, I wish to retract my News and Views article, which dealt with this study and was based on the accuracy and reproducibility of its data.

\section{ERRATUM}

\section{Chemical reporters for biological discovery}

Markus Grammel and Howard C Hang

Nat. Chem. Biol. 9, 475-484 (2013); published online 18 July 2013; corrected after print 19 December 2013

In the version of this Review Article initially published, a double bond was missing from the chemical structure of the cyclooctene on the left side of the reaction arrow in Figure 1e. The chemical structure has been corrected in the HTML and PDF versions of the article. 